\title{
In Memoriam: Prof. Dr. Hanns Kreisel (1931-2017)
}

\author{
Ulrike Lindequist \& Frieder Schauer \\ Ernst-Moritz-Arndt University Greifswald, Greifswald, Germany
}

Prof. Dr. Hanns Kreisel, one of the most important German mycologists and a professor of botany at the Ernst-Moritz-Arndt University Greifswald, died in January 2017. His great international reputation was demonstrated by, for example, his guest professorship in Cuba between 1968 and 1971; guest lectures in Mexico, Argentina, Spain, and other countries; a number of international collaborations; membership in international organizations, including the European Council for Conservation of Fungi, and on several editorial boards; and, of course, his wellknown books and publications. In his honor, 8 taxa of fungi were named "Kreiseliella," "kreiselii," or "kreiseliana."

Hanns Kreisel was born in Leipzig and studied geology and biology in Greifswald (1951-1956). During his appointment at the Ernst-Moritz-ArndtUniversity of Greifswald, he published, coauthored, or edited more than 20 books, among them the 6volume Handbuch für Pilzfreunde (5 editions). His book Grundzüge eines natürlichen Systems der Pilze, published in 1969, is still today a basic resource for mycologists worldwide. In that book, the thesis that fungi constitute an autonomous kingdom was vigorously argued, and today this is now generally accepted.

Dr. Kreisel connected very early the fields of plant sociology, geobotany, and mycology and can be considered the founder of mushroom mapping in Eastern Germany (1957 and later). His main fields of interest, in addition to Special Botany as a lecture field, were the taxonomy and biogeography of fungi, especially Basidiomycetes (e.g., Lycoperdaceae and the genus Bovista). Later, he integrated microscopic small fungi such as molds into his studies. The books Pilzflora der Deutschen Demokratischen Republik (1987) and Pilze von Mecklenburg-Vorpommern (2011) stimulated similar books concerning other regions; the laboratory handbook Methoden des

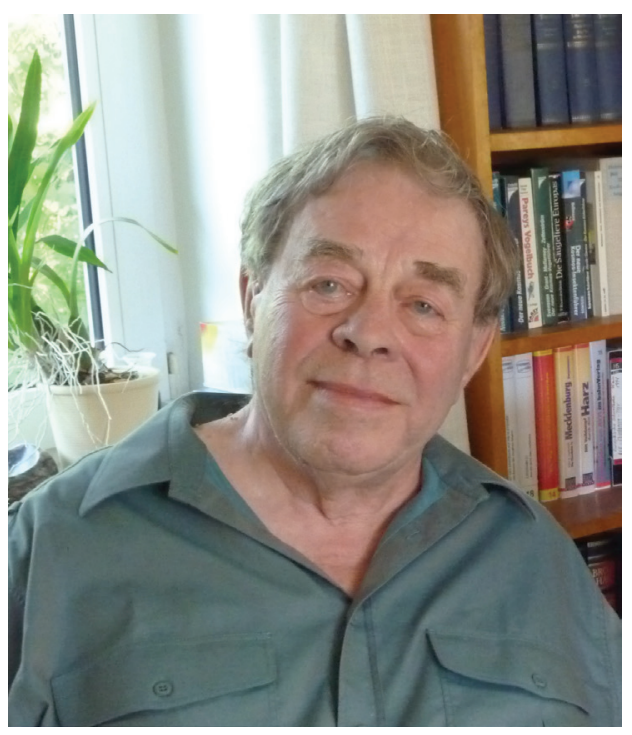

Prof. Dr. Hanns Kreisel

(Credit: Dr. Lebrecht Jeschke)

mykologischen Laboratoriums (1987) gave a variety of valuable hints for experimental working mycologists. In addition to books, Dr. Kreisel published more than 300 scientific publications covering a broad spectrum of topics: from systematics of fungi and plants, to experimental mycology, paleomycology, and applied mycology, to ethnomycological, medicinal, and cultural aspects of fungi. His last book, Ethnomykologie. Verzeichnis der ethnomykologisch, biotechnologisch und toxikologisch relevanten Pilze. Literatur-Kunst-VolksmedizinPharmazie-Techniken-Drogen-Toxine-Farbstoffe (Ethnomycology. Register of ethnomycologically, biotechnologically and toxicologically relevant fungi. literature-art-ethnomedicine-pharmacy-techniquesdrugs-toxins-pigments), was published in 2014 and impressively demonstrates his immense knowledge of very different fields and his ability to collect, analyze, and communicate data. We hope that this informative 
book will be published in English and thereby be made accessible to readers all over the world.

The name of Hanns Kreisel is also connected with extensive field mapping of mushrooms in various regions and much guiding work for voluntary mushroom advisers and others. Prof. Kreisel, together with Dr. Mohamed Al-Fatimi, built the base for mushroom mapping in Yemen. It is in no small measure because of him that exact and sciencebased mycology achieved positive development in many countries.

It was a privilege for us to work with Hanns Kreisel and to profit from his knowledge and his humanity. We, and many other people all over the world, owe a great debt to Prof. Hanns Kreisel and will not forget him. 